Keywords: colorectal cancer; mismatch repair; fluoropyrimidine; thymidylate synthase; dihydropyrimidine dehydrogenase; gene expression

\title{
Molecular patterns in deficient mismatch repair colorectal tumours: results from a French prospective multicentric biological and genetic study
}

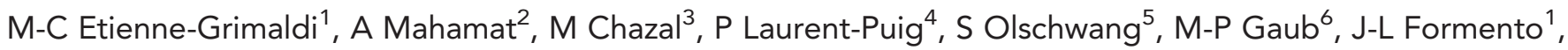
P Formento ${ }^{1}$, A Sudaka ${ }^{1}$, V Boige ${ }^{7}$, A Abderrahim-Ferkoune ${ }^{2}, \mathrm{D} \mathrm{Benchimol}^{2}$, T André ${ }^{8}$, S Houry ${ }^{8}$, J-L Faucheron ${ }^{9}$, C Letoublon ${ }^{9}$, F-N Gilly ${ }^{10}$, J-R Delpero ${ }^{11}$, P Lasser ${ }^{7}$, B Pradere ${ }^{12}$, D Pezet ${ }^{13}$, F Penault-Llorca ${ }^{14}$ and G Milano*,1

${ }^{1}$ Oncopharmacology and Pathology Departments, Centre Antoine-Lacassagne, Nice, France; ${ }^{2}$ Surgery Department, CHU Nice, Nice, France; ${ }^{3}$ Clinique Saint-George, Nice, France; ${ }^{4}$ Inserm U490, Hôpital Georges Pompidou, Paris, France; ${ }^{5}$ Inserm UMR 1068 (CRCM), CHU Timone, Marseille, France; ${ }^{6}$ Inserm U381, CHRU de Strasbourg, Strasbourg, France; ${ }^{7}$ Institut Gustave Roussy, Villejuif, France; ${ }^{8}$ Hôpital St Antoine, Paris, France; ${ }^{9}$ Surgery Department, CHU Grenoble, Grenoble, France; ${ }^{10}$ Surgery Department, CHU Lyon Sud, Lyon, France; ${ }^{11}$ Surgery Department, Institut Paoli Calmettes, Marseille, France; ${ }^{12}$ Surgery Department, CHU Toulouse, Toulouse, France; ${ }^{13}$ Surgery Department, CHU Clermont-Ferrand, Clermont-Ferrand, France and ${ }^{14}$ Pathology Department, Centre Jean Perrin, Clermont-Ferrand, France

Background: To test the prognostic value of tumour protein and genetic markers in colorectal cancer (CRC) and examine whether deficient mismatch repair (dMMR) tumours had a distinct profile relative to proficient mismatch repair (pMMR) tumours.

Methods: This prospective multicentric study involved 251 stage I-III CRC patients. Analysed biomarkers were EGFR (binding assay), VEGFA, thymidylate synthase (TS), thymidine phosphorylase (TP) and dihydropyrimidine dehydrogenase (DPD) expressions, MMR status, mutations of KRAS (codons 12-13), BRAF (V600E), PIK3CA (exons 9 and 20), APC (exon 15) and P53 (exons 4-9), CpG island methylation phenotype status, ploidy, S-phase, LOH.

Results: The only significant predictor of relapse-free survival (RFS) was tumour staging. Analyses restricted to stage III showed a trend towards a shorter RFS in KRAS-mutated $(P=0.005), B R A F$ wt $(P=0.009)$ and pMMR tumours $(P=0.036)$. Deficient mismatch repair tumours significantly demonstrated higher TS (median 3.1 vs 1.4) and TP (median 5.8 vs 3.5) expression relative to pMMR $(P<0.001)$ and show higher DPD expression (median 14.9 vs 7.9, $P=0.027$ ) and EGFR content (median 69 vs 38, $P=0.037$ ) relative to $p M M R$.

Conclusions: Present data suggesting that both TS and DPD are overexpressed in dMMR tumours as compared with pMMR tumours provide a strong rationale that may explain the resistance of dMMR tumours to 5FU-based therapy.

Colorectal cancer (CRC) is heterogeneous with regard to genetic alterations (Grady and Carethers, 2008; Cancer Genome Atlas Network, 2012), suggesting distinct natural histories emerging from different genetic instabilities. Burrell et al (2013) have recently suggested that replication stress and chromosome segregation errors may promote intratumour genetic heterogeneity. 
The majority of sporadic CRC display chromosomal instability, whereas $\sim 15 \%$ of sporadic cases exhibit microsatellite instability resulting from deficiencies in mismatch repair (MMR) enzymes. This deficient MMR (dMMR) status is associated with a favourable prognosis irrespective of tumour staging (Popat et al, 2005; Bertagnolli et al, 2011; Hutchins et al, 2011; Roth et al, 2012; Sinicrope and Sargent, 2012). So far, among potential biomarkers that could guide the decision to initiate adjuvant CRC treatment, none has been validated with sufficient level of evidence for routine use, and pathologic tumour staging is still considered to be the main prognostic factor in current practice (Ueno et al, 2012). Adjuvant treatment is currently a standard in stage III CRC. For stage II CRC (tumours without apparent lymph node metastasis), the majority of patients will be cured by surgery alone, whereas a subset of patients will develop recurrence. The QUASAR randomized study demonstrated that adjuvant fluorouracil (5FU)-folinic acid treatment significantly improved survival of stage II CRC patients; however, absolute improvement was small (Quasar Collaborative Group et al, 2007). Thus, there is still a need to identify prognostic and predictive biomarkers for optimal personalised medicine in CRC, particularly in stage II patients.

This was the challenge we faced when launching this prospective study, such studies being considered the gold standard (Van Schaeybroeck et al, 2011). This French multicentric study included 256 stage I-III CRC patients who received, or not, adjuvant chemotherapy. The primary objective was to test prognostic/ predictive markers covering relevant protein expression and genetic abnormalities. Since MMR status not only influences prognosis (Popat et al, 2005; Bertagnolli et al, 2011; Hutchins et al, 2011; Roth et al, 2012; Sinicrope and Sargent, 2012) but also sensitivity to fluoropyrimidine-based adjuvant treatment (Ribic et al, 2003; Popat et al, 2005; Sargent et al, 2010), our intention was also to examine whether dMMR tumours exhibit a distinct protein profile as compared with proficient MMR (pMMR) tumours. Such a broad prospective multiparametric approach has seldom been reported.

\section{MATERIALS AND METHODS}

Patients. This French prospective multicentric study (nine hospitals) was conducted in 251 out of 256 CCR patients included between May 1995 and November 2002 (last follow-up November 2008). All presented non-metastatic histologically documented adenocarcinoma (stages I-III) of the colon (or non-irradiated rectum) with complete surgical resection. Non-inclusion criteria included known hereditary non-polyposis colorectal cancer (HNPCC). The choice of adjuvant chemotherapy was guided according to institutional practices. Patients must have received no previous chemotherapy and present no other malignant tumour. The study was conducted in accordance with the Good Clinical Practice guidelines (ethics committee approval, written informed consent). For all patients, primary tumour was collected at the time of surgery. Normal colorectal mucosa was collected in 137 patients. Histological control, performed on 87 tumour samples, showed that $94 \%$ of samples fully fitted histological quality criteria $(>40 \%$ tumour cells and good quality). The five tumours that did not meet histological quality prerequisites were excluded from the analysis; analyses were thus performed on 251 patients.

Tumoral analyses. Tumours (100-200 mg) were immediately frozen and stored in liquid nitrogen. Tumour handling is described in the Supplementary Material, as well as flow cytometry analysis (ploidy and S-phase fraction). EGFR concentrations in crude membranes were analysed by a ligand-binding assay based on competition between ${ }^{125}$ I-EGF and unlabelled EGF (Santini et al,
1991). The sensitivity limit was $1 \mathrm{fmol} \mathrm{mg}^{-1}$ protein. Thymidylate synthase (TS) activity was measured in the cytosol according to the tritium-release assay (Etienne et al, 2002). The sensitivity limit was $10 \mathrm{fmol} \mathrm{min}^{-1}$ per mg protein. Tumour VEGFA expression was measured in the cytosol using the Human VEGF Quantikine ELISA kit from R\&D Systems Inc. (Minneapolis, $\mathrm{MN}$, USA) (Onesto et al, 2006). The quantification limit was $15 \mathrm{pg} \mathrm{ml}^{-1}$.

Tumoral DNA analyses, namely KRAS mutations (codons 12-13), BRAF V600E mutation, P53 mutations (exon 4 to exon 9), PIK3CA mutations (exons 9 and 20), MMR status, allelic loss (LOH) on chromosomes $8 \mathrm{p}, 17 \mathrm{p}, 18 \mathrm{q}$ and $\mathrm{CpG}$ island methylation phenotype (CIMP), are detailed in the Supplementary Material. LOHs were only analysed on the subgroup of patients with available normal mucosa.

Tumour expression levels of TS, thymidine phosphorylase (TP) and dihydropyrimidine dehydrogenase (DPD) were measured using quantitative real-time RT-PCR, using the GAPDH gene as reference (see details in Supplementary Materials). The sensitivity limit was 0.05 arbitrary units for TS and TP, and 0.5 arbitrary units for DPD.

Normal mucosa analyses. Normal mucosas (100-200 mg) were handled like tumour samples and resulting DNAs were analysed for candidate-gene polymorphisms.

Gene polymorphism analyses. The following gene polymorphisms were analysed on tumour DNA (251 patients): TYMS (5'-UTR $28 \mathrm{bp}$, rs34743033; G $>\mathrm{C}$ mutation in the $3 \mathrm{R}$ allele, rs11540151; 3'-UTR 6 bp deletion, rs11280056), methylene tetrahydrofolate reductase (MTHFR $677 \mathrm{C}>\mathrm{T}$, rs 1801133 and 1298A > C, rs1801131), EGFR (intron 1 CA repeats, rs11568315; $-216 \mathrm{G}>\mathrm{T}$, rs712829; $-191 \mathrm{C}>\mathrm{A}$, rs712830 and 497Arg $>$ Lys, rs $2227983)$ and the EGF gene $(61 \mathrm{~A}>\mathrm{G}$, rs 4444903). For TYMS 5 -UTR genotype, patients were classified as a function of the number of theoretical E-box-binding sites likely to bind USF proteins: class 2 (2R2R or $2 \mathrm{R} 3 \mathrm{RC}$ or $3 \mathrm{RC} 3 \mathrm{RC}$ ), class 3 (2R3RG or $3 R C 3 R G)$ and class 4 (3RG3RG). For EGFR intron 1 polymorphism, patients were split into three groups: both alleles $<17 v s$ both alleles $\geqslant 17 v s$ others. In addition, analyses were performed on paired-normal mucosa DNA for 137 patients.

Statistics. $\chi^{2}$-tests for Hardy-Weinberg equilibrium (bi-allelic genotypes) were performed on http://www.oege.org/software/ hwe-mr-calc.shtml. The distribution of quantitative tumour markers - that is, EGFR, VEGFA, TS activity, TS, TP and DPD expressions - did not fit a Gaussian distribution and were analysed as continuous variables using non-parametric tests. Relationships between continuous variables were analysed by means of Spearman rank correlations. The impact of categorical variables on continuous variables was tested by means of Mann-Whitney test or Kruskall-Wallis test (exact $P$-values computed according to the Monte Carlo method). Links between categorical variables were assessed by Fisher's Exact tests. For statistics, genotypes were considered as ternary categorical variables, with the exception of EGFR $-216 \mathrm{G}>\mathrm{T}$ and $-191 \mathrm{C}>\mathrm{A}$ genotypes, both considered as binary variables (rare homozygous cases merged with heterozygous cases).

The primary efficacy variable was relapse-free survival (RFS), computed from the date of surgery until the date of first relapse defined as local recurrence or metastasis (deaths were not considered with the exception of one patient lost to follow-up who died from his cancer). Median follow-up was computed according to the inverse Kaplan-Meier method. Comparison of RFS between groups was tested by the log-rank test adjusted for tumour staging. Univariate and multivariate Cox proportional hazard regression models were also applied for testing categorical or Gaussian continuous variables (that is, $\log 10$-transformed TS, 
TP and DPD expression, and EGFR) and for estimating relative risks (RRs) along with 95\% confidence intervals (CIs 95\%). For survival analyses, quantitative tumour markers were also analysed as binary variables according to their median values $(\leqslant v s$ $>$ median). For stepwise multivariate analyses, both forward and backward analyses were performed ( $P=0.05$ for entry, $P=0.10$ for removal). All tests were two-sided. All $P$-values $<0.050$ were reported. At the time of study initiation and sample size calculation (300 patients), the number of prognostic biomarker to be tested was limited (TS, P53 mutation, S-phase). Owing to the enlargement of tested variables subsequent to knowledge evolution, we have thus considered a $P$-value as significant when $\leqslant 0.001$ (Bonferroni correction). We considered $P$-values comprised between 0.001 and 0.05 as indicating tendencies. Statistics was drawn up on the SPSS software v 15.0 (Paris, France).

\section{RESULTS}

Patient and tumour characteristics. Patient description is given in Table 1. There were 30 stage I, 116 stage II and 105 stage III patients. The mean age was 69.1 (extremes 29-90). The S-phase fraction, assessable on 204 tumours, ranged from 1.46 to $50 \%$ (mean 17.6, median 17). Tumour localisation was significantly linked to tumour staging (right/transverse colon being preferentially stage III, $P<0.001$ ). A trend towards an association was observed between the ploidy status and tumour localisation (aneuploid or multiploid status in $48 \%$ of right/transverse colon vs $69 \%$ in left/sigmoid/RS junction $v s 76 \%$ in rectum, $P=0.004$ ) or histology (mucinous adenocarcinoma more frequently diploid $(68.8 \%)$ than non-mucinous adenocarcinoma $(36 \%, P=0.048))$.

Adjuvant 5FU-based chemotherapy was administered in $25.9 \%$ of stage II and $58.1 \%$ of stage III patients. The median interval between surgery and chemotherapy onset was 41 days. The median follow-up was 88 months. At the time of analysis, 60 patients had developed metastasis or recurrence and 91 patients had died.

Among conventional histoprognostic factors, only tumour staging was significantly linked to RFS in univariate $(R R=5.7$ and 12.6 for stages II and III, respectively, as compared with stage I; $P=0.001$, Supplementary Figure S1A) and multivariate analyses. A trend was observed towards a longer RFS in left/sigmoid/RS junction tumours $(\mathrm{RR}=0.67$ and 1.6 for left/sigmoid/RS junction and rectum, respectively, as compared with right/transverse; $P=0.029$, Supplementary Figure S1B). A log-rank analysis adjusted for tumour staging and restricted to stage II-III patients showed no significant impact of chemotherapy. A multivariate Cox analysis confirmed the absence of interaction between chemotherapy and tumour staging.

Analysis of tumour DNA features. Results of MMR, CIMP, mutation and allelic loss analyses, and their relationships with tumour localisation and histology, are presented in Supplementary Table S2. None of these DNA molecular features were significantly related to tumour staging. Deficient mismatch repair tumours were observed in $14 \%$ of patients. Deficient mismatch repair status was significantly associated with the right/transverse colon $(P<0.001)$ and diploid tumours $(P<0.001)$. A tendency towards an elevated dMMR rate in mucinous adenocarcinoma was observed $(P=0.023)$. P53 mutations $(48.8 \%$ in total) were less frequent in the right/transverse colon $(P<0.001)$ and diploid tumours $(P<0.001)$. The $\mathrm{S}$-phase fraction was significantly higher in $\mathrm{p} 53$ mutated tumours as compared with p53 wt tumours (median $21 \%$ vs $11 \%$, respectively; $P<0.001$ ). We observed $32.7 \%$ of KRAS mutations at codons 12 and 13, which were mutually exclusive of BRAF V600E mutation found in $9.6 \%$ of tumours $(P<0.001)$. KRAS and BRAF mutations were more frequent in the right/ transverse colon $(P<0.001$ and 0.004 , respectively). BRAF

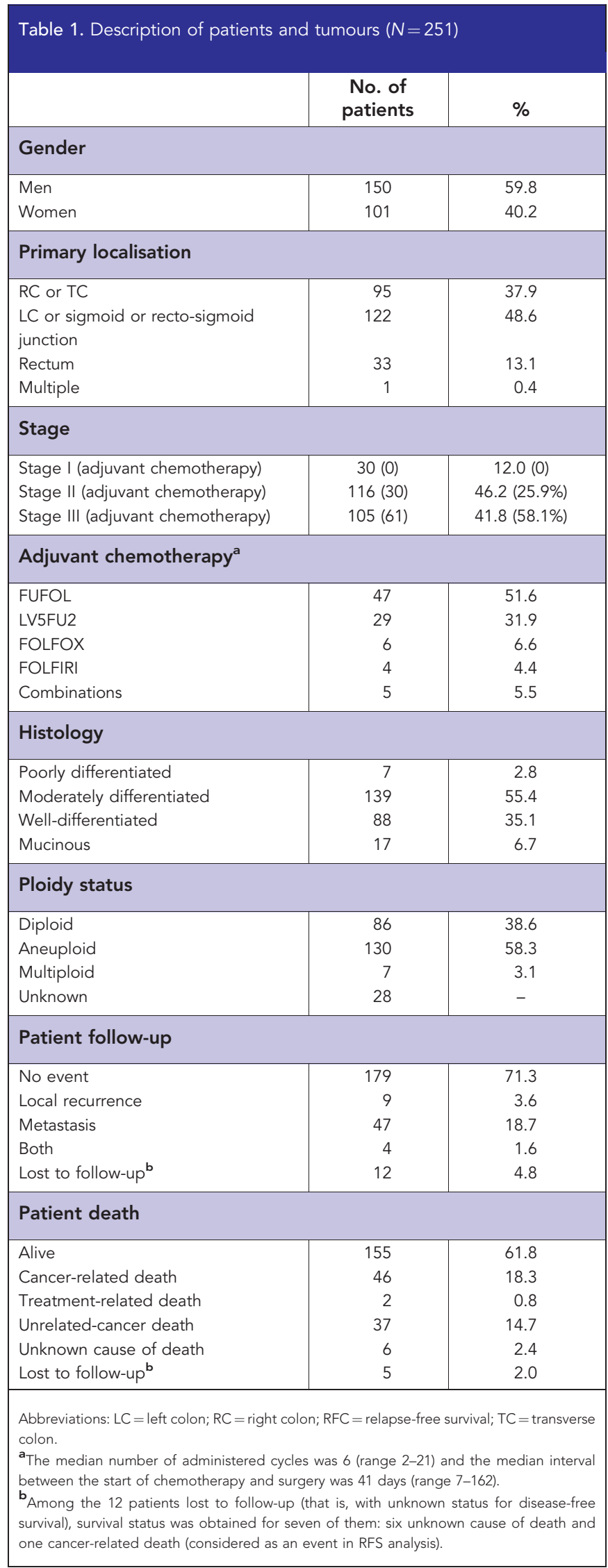

mutations were more frequent in diploid tumours $(P<0.001)$ and in poorly/moderately differentiated tumours $(P=0.002)$. A tendency towards a lower rate of APC mutations (75.4\% in total) 
was observed in diploid tumours $(57 \%, P=0.034)$. In contrast, a trend towards a higher rate of PIK3CA mutations (12.3\% in total) was observed in diploid tumours $(20.3 \%, P=0.012)$. CIMP phenotype was identified in $17.7 \%$ of patients and was significantly associated with right/transverse colon $(P<0.001)$.

Associations between tumour DNA features are detailed in Supplementary Table S3. Deficient mismatch repair tumours were significantly prone to be p53 wt, BRAF-mutated and CIMPpositive $(P<0.001)$. All dMMR tumours were APC wt $(P=0.011)$. Deficient mismatch repair tumours tended to be KRAS wt $(82.4 \%$ in dMMR vs $64.6 \%$ in pMMR tumours, $P=0.049)$. BRAF mutation status was significantly linked to p53 wt status $(P<0.001)$. All BRAF-mutated tumours were CIMP-positive $(P<0.001)$. P53mutated tumours were significantly prone to present allelic loss on $8 \mathrm{p}, 17 \mathrm{p}$ and $18 \mathrm{q}(P<0.001)$

None of the above DNA features had a significant impact on RFS in univariate analyses adjusted for tumour staging. Analyses restricted to stage II patients did not reveal significant impact of MMR status, and KRAS or BRAF mutation status (Supplementary Figure S2, Figure 1A). In contrast, analyses restricted to stage III patients showed a tendency towards a longer RFS in dMMR tumours (log-rank, $P=0.036$, Figure 2A), KRAS wt tumours (log-rank, $P=0.005$, Figure $2 \mathrm{~B}$ ) and, unexpectedly, in BRAF-mutated tumours (log-rank, $P=0.009$, Figure $1 \mathrm{~B})$. An analysis restricted to stage III patients with KRAS wt tumours confirmed the trend towards a better RFS in BRAF-mutated tumours $(P=0.02)$.

Analysis of tumour expression features. Table 2 illustrates the relationships between quantitative tumour expression (EGFR, VEGFA, TS, TP and DPD) and tumour characteristics. Both TS and DPD expression levels showed a trend towards an association with tumour staging (lower in stage I) and with tumour localisation (greater in the right/transverse colon, reaching significance for DPD with $P<0.001)$. EGFR expression also showed a tendency towards greater levels in the right/transverse colon ( $v s$ the left colon and rectum), and for lower levels in mucinous tumours ( $v s$ others). A two-fold higher DPD expression was observed in mucinous tumours ( $v s$ others, $P=0.005$ ). TS, TP and DPD expression levels were higher in diploid tumours (vs aneuploid/multiploid tumours, significant for TS expression, $P<0.001)$. In addition, trends towards correlations between the S-phase fraction and cytosolic VEGFA concentrations $(r=+0.17$, $P=0.015)$ or DPD expression $(r=-0.19, \quad P=0.009)$ were observed.

The strongest correlations between tumour expression features were observed between DPD expression and TP expression $(r=0.38, P<0.001)$ as well as between DPD expression and TS activity $(r=-0.23, P<0.001)$ (Supplementary Table S4).

Table 3 illustrates the relationships between expression markers and tumour DNA features. Deficient mismatch repair tumours were significantly associated with elevated TS and TP expression $(P<0.001)$ and showed a trend to express high DPD $(P=0.027)$, high TS activity $(P=0.004)$ and high EGFR $(P=0.037)$. P53 wt tumours were significantly associated with elevated TS and DPD expression $(P<0.001)$. CIMP-positive tumours were significantly associated with elevated TS activity $(P=0.001)$. LOH on $17 \mathrm{p}$ was significantly associated with elevated VEGFA concentration and low DPD expression $(P=0.001)$.

None of these expression markers had a significant impact on RFS (taken as continuous variables, or binary variables, with adjustment for tumour staging). Analyses restricted to stage II-III patients, adjusted for tumour staging and adjuvant therapy, did not reveal any significant impact of TS activity or TS expression on RFS.

Analysis of gene polymorphisms. Gene polymorphism data are detailed in Supplementary Material (Supplementary Table S1). No significant relationship was observed between any of the genotypes
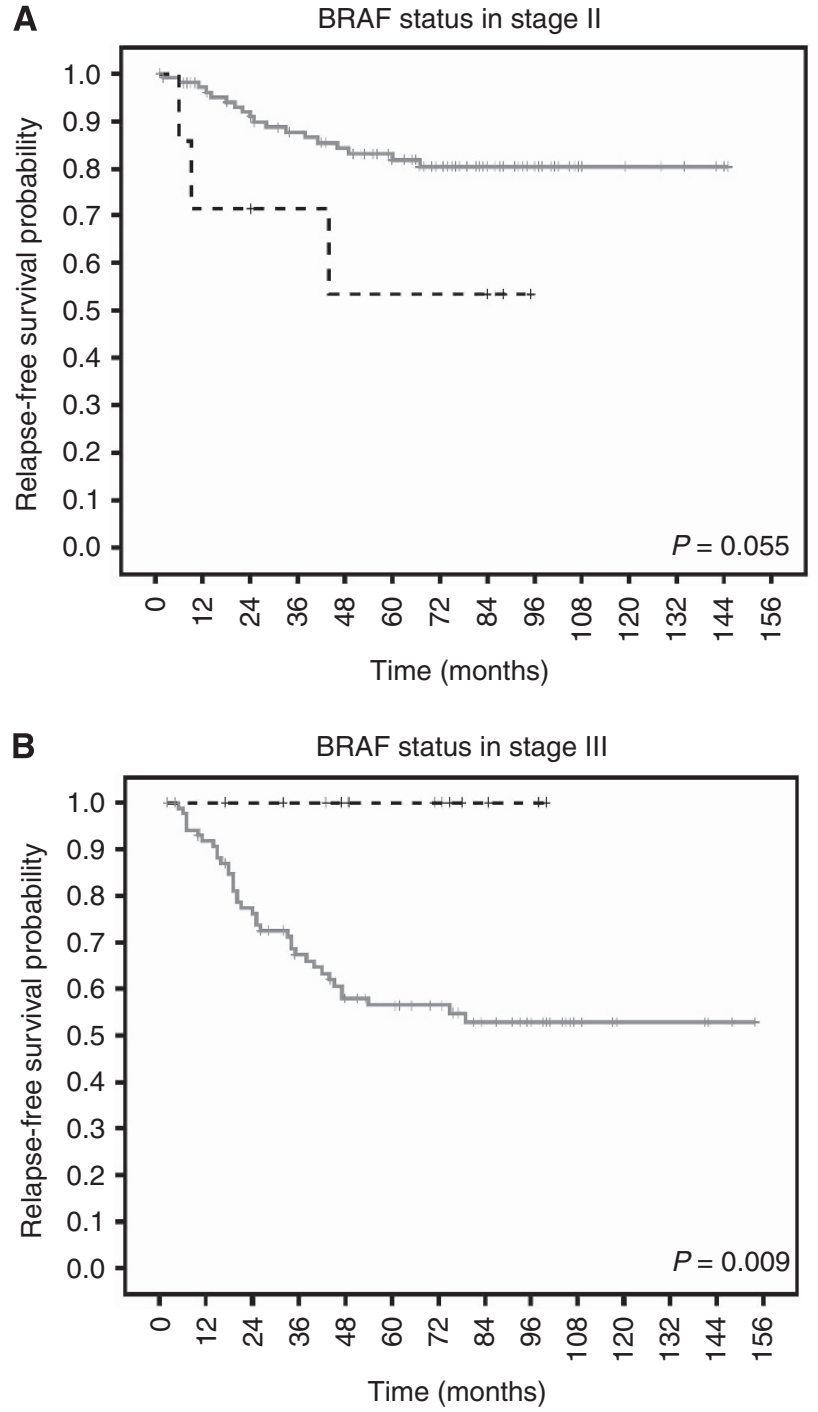

Figure 1. Relapse-free survival probability according to BRAF mutation status in stage II (A) and stage III (B) patients. Overall logrank test adjusted for tumour staging (stages $I I-I I I), P=0.11$. (A) Stage II patients with BRAF wt tumour (full green line, 104 patients, 18 events) or BRAF-mutated tumour (dotted black line, seven patients, three events): log-rank: $P=0.055$. Analysis restricted to the 75 stage II patients with KRAS wt tumour (68 BRAF wt, 14 events; 7 BRAF-mutated, 3 events): log-rank, $P=0.14$. (B) Stage III patients with BRAF wt tumour (full green line, 87 patients, 37 events) or BRAF-mutated tumour (dotted black line, 13 patients, 0 event): log-rank, $P=0.009$. Analysis restricted to the 63 stage III patients with KRAS wt tumour (50 BRAF wt, 18 events; 13 BRAF-mutated, 0 events) showed a similar pattern: log-rank, $P=0.022$. The full colour version of this figure is available at British Journal of Cancer online.

and expression markers or other tumour characteristics. None of the above genotypes had a significant impact on RFS in univariate analyses adjusted for tumour staging.

\section{DISCUSSION}

Various prognostic and/or predictive signatures based on targeted molecular markers or gene expression profiles have been tested in CRC (Van Schaeybroeck et al, 2011). With the exception of dMMR status, which is reproducibly associated with a good prognosis (Popat et al, 2005; Bertagnolli et al, 2011; Hutchins et al, 2011; 


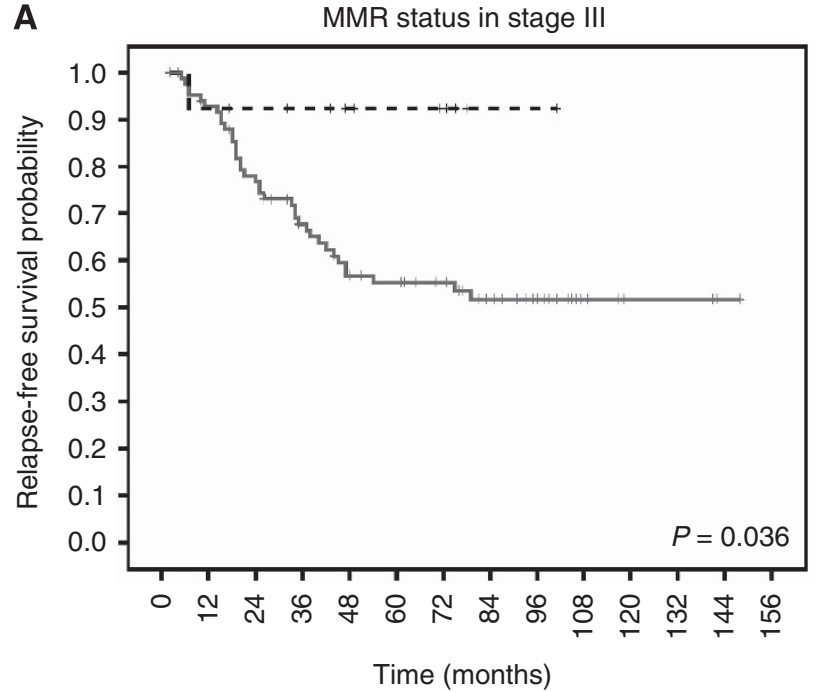

B

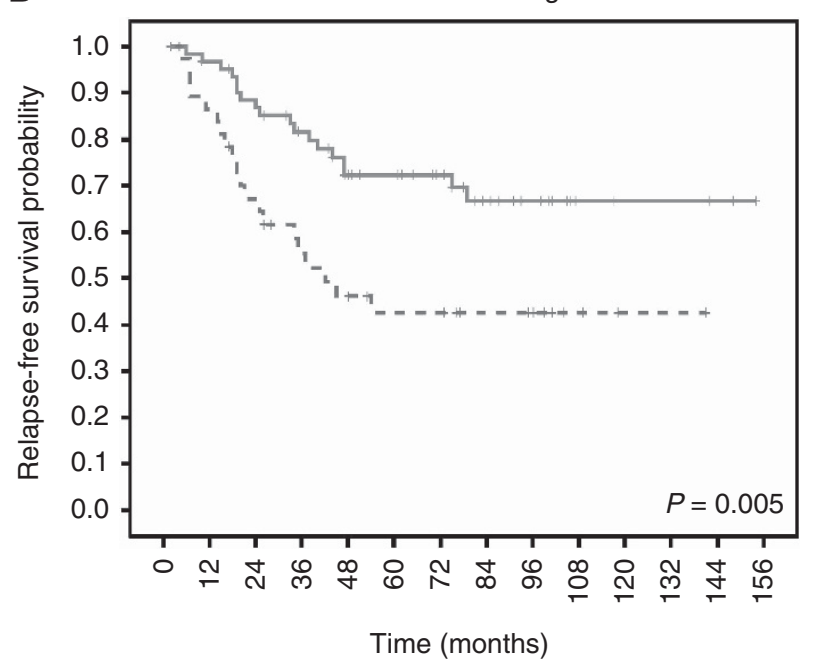

Figure 2. Relapse-free survival probability in stage III patients according to MMR status (A) and KRAS status (B). (A) Stage III patients with pMMR (full blue line, 85 patients, 37 events) or dMMR tumour (dotted black line, 13 patients, 1 event): log-rank, $P=0.036$. Overall log-rank test performed on stages II-III patients and adjusted for tumour staging: $P=0.18$. (B) Stage III patients with KRAS wt tumour (full green line, 63 patients, 18 events) or KRAS-mutated tumour (dotted red line, 38 patients, 20 events): log-rank, $P=0.005$. Relative risk $=2.40(95 \% \mathrm{Cl} 1.27-4.55)$ for KRAS mut as compared with KRAS wt (Cox, $P=0.007$ ). Overall log-rank test performed on stages II-III patients and adjusted for tumour staging: $P=0.21$. Multivariate Cox analysis conducted on stages II-III patients revealed an interaction between KRAS status and tumour staging $(P=0.046)$. The full colour version of this figure is available at British Journal of Cancer online.

Sinicrope et al, 2011, 2013; Roth et al, 2012; Sinicrope and Sargent, 2012), the clinical management of CRC is still based on clinicopathological staging (Ueno et al, 2012). We analysed 251 frozen tumour samples prospectively collected from stage I-III sporadic CRC patients who received or not 5FU-based chemotherapy according to physician's practice. The relevance of this study lies in the decision to administer adjuvant therapy reflecting daily therapeutic management and, more globally, in the truly prospective nature of this biological marker study. We investigated not only tumour DNA characteristics but also, less frequently, proteins that are targeted by current therapies approved in CRC, namely, VEGFA (bevacizumab target) and EGFR (cetuximab and panitumumab target), as well as markers involved in fluoropyrimidine pharmacology, namely TS (main 5FU target), DPD (key enzyme of 5FU catabolism) and TP (involved in pyrimidine anabolism). EGFR was measured by a ligand-binding assay that quantifies high-affinity binding sites, as we previously reported that EGFR binding sites correlated with anti-EGFR efficacy in vitro (Magné et al, 2002) and that EGFR IHC analysis only partially reflects the presence of functional EGFR quantified with a binding assay (Etienne-Grimaldi et al, 2006). To our knowledge, this is the first such multifaceted biological prospective study conducted to date in CRC.

The frequencies of analysed somatic mutations with $12 \%$ PIK3CA mutations at exons 9 and 20,33\% KRAS mutations at codons $12-13$ and 9.6\% BRAF V600E mutations, closely matched the literature data (Hutchins et al, 2011; Roth et al, 2012; Liao et al, 2012). Thirty-four tumours out of the 243 analysed for MMR status exhibited the dMMR status, accounting for $14 \%$, a figure that closely matches the literature data (Hutchins et al, 2011; Roth et al, 2012; Sinicrope and Sargent, 2012; Merok et al, 2013; Sinicrope et al, 2013). None of these 34 dMMR tumours were known HNPCC, 18 were BRAF-mutated indicating sporadic cancer, and among the remaining 16 BRAF wt only five patients were below 50-years old suggesting a possible HNPCC. According to the literature data (Van Schaeybroeck et al, 2011), dMMR status was significantly associated with right colon localisation, $B R A F$ mutation, P53 wt, CIMP-positive and diploidy (all $P<0.001$ ), and significant inter-relationships between the above-cited markers were highly consistent with each other.

None of these markers had a significant impact on RFS adjusted for tumour staging. Analyses restricted to stage II patients did not reveal significant relationships. In contrast, analyses restricted to stage III patients showed a strong tendency towards a shorter RFS in patients bearing KRAS-mutated tumours $(P=0.005$, Figure $2 \mathrm{~B})$ or $B R A F$ wt tumours $(P=0.009$, Figure $1 \mathrm{~B})$, and a weak tendency towards a longer RFS in dMMR tumours $(P=0.036$, Figure $2 \mathrm{~A})$. Even though the prognostic value of KRAS mutation in CRC patients remains controversial (Andreyev et al, 1998, 2001; Richman et al, 2009; Ogino et al, 2009a; Roth et al, 2010; Gavin et al, 2012; Eklöf et al, 2013), a study conducted on more than 1500 stage II CRC patients from the QUASAR trial (FU/FA vs observation) reported a significantly increased risk of recurrence in KRAS-mutated tumours, irrespective of adjuvant chemotherapy (Hutchins et al, 2011). More consistent is the prognostic value of BRAF V600E mutation, most studies having reported a poorer overall survival in BRAF-mutated tumours whatever the tumour staging (Richman et al, 2009; Souglakos et al, 2009; Ogino et al, 2009b; Roth et al, 2012; Gavin et al, 2012), whereas two of them conducted on stage II-III colon cancer receiving 5FU-based adjuvant therapy showed that RFS was not associated with BRAF mutations (Roth et al, 2012; Gavin et al, 2012). Our data show that among the 13 stage III BRAF-mutated tumours, 9 were dMMR. This limited population did not allow us to further discriminate between the impact of BRAF mutation itself and dMMR status. In this regard, relevant information is provided by the study by Gavin et al (2012) reporting that the poor prognostic values of BRAF mutation and pMMR status were additive. This absence of interaction between BRAF and MMR status on specific survival, or overall survival, was recently confirmed (Lochhead et al, 2013).

Tumour samples were also analysed for the S-phase fraction and TS, TP, DPD, EGFR and VEGFA expression. None of these markers, or gene polymorphisms, had a significant impact on RFS. Numerous studies have explored the predictive/prognostic value of tumour TS expression (IHC or RT-PCR) in CRC patients receiving/ not receiving 5FU-based therapy, with conflicting results (Popat et al, 2004). As shown in the meta-analysis by Popat et al (2004), a majority of studies (9 out of 13) conducted in the metastatic 
Table 2. Description of tumoral expression features and significant association with classical tumour characteristics ${ }^{\mathbf{a}}$

\begin{tabular}{|c|c|c|c|c|c|c|c|c|c|c|c|}
\hline & \multicolumn{3}{|c|}{ Tumour stage } & \multicolumn{3}{|c|}{ Tumour localisation } & \multicolumn{3}{|c|}{ Tumour histology } & \multicolumn{2}{|r|}{ Ploidy } \\
\hline $\begin{array}{c}\text { All } \\
\text { patients }\end{array}$ & $\mathrm{I}$ & II & III & $\mathrm{RC} / \mathrm{TC}$ & LC/Sig/RSJ & Rectum & $\begin{array}{l}\text { Poorly/moderately } \\
\text { differentiated }\end{array}$ & Well differentiated & Mucinous & Diploid & $\begin{array}{l}\text { Aneuploid or } \\
\text { multiploid }\end{array}$ \\
\hline
\end{tabular}

\begin{tabular}{|c|c|c|c|c|c|c|c|c|c|}
\hline \multicolumn{10}{|c|}{ Membranous EGFR (fmol $\mathrm{mg}^{-1}$ protein) } \\
\hline Median & 40 & & 58 & 36 & 37 & 47 & 37 & 24 & \\
\hline Mean & 60 & & 66 & 57 & 51 & 64 & 57 & 40 & \\
\hline Extremes & $1-516$ & & & & & & & & \\
\hline $\mathrm{N}$ & 245 & & 92 & 120 & 32 & 142 & 86 & 17 & \\
\hline Statistics & & NS & & $P=0 . C$ & & & & & NS \\
\hline
\end{tabular}

Cytosolic VEGF (pg mg ${ }^{-1}$ protein)

\begin{tabular}{|c|c|c|c|c|c|c|}
\hline $\begin{array}{l}\text { Median } \\
\text { Mean } \\
\text { Extremes } \\
\mathrm{N}\end{array}$ & $\begin{array}{c}289 \\
504 \\
\text { ND to } 4685 \\
251\end{array}$ & & & & $\begin{array}{l}247 \\
440 \\
\\
86\end{array}$ & $\begin{array}{r}342 \\
528 \\
\\
137\end{array}$ \\
\hline Statistics & & NS & NS & NS & \multicolumn{2}{|c|}{$P=0.029$} \\
\hline
\end{tabular}

Cytosolic TS activity (fmol $\mathrm{min}^{-1}$ per $\mathrm{mg}$ protein)

\begin{tabular}{|l|c|c|c|c|c|}
\hline Median & 1074 & & & \\
Eean & 1712 & & & \\
Extremes & ND to 12118 & & & \\
N & 251 & & & & \\
\hline Statistics & & NS & NS & & NS \\
\hline
\end{tabular}

mRNA TS expression (a.u.)

\begin{tabular}{|c|c|c|c|c|c|c|c|c|c|c|}
\hline Median & 1.51 & 0.97 & 1.63 & 1.45 & 1.79 & 1.39 & 1.23 & & 2.12 & 1.32 \\
\hline Mean & 2.25 & 2.25 & 2.61 & 1.82 & 2.65 & 2.13 & 1.57 & & 2.87 & 1.68 \\
\hline Extremes & $0.05-22.50$ & & & & & & & & & \\
\hline $\mathrm{N}$ & 238 & 29 & 113 & 96 & 89 & 117 & 31 & & 83 & 132 \\
\hline Statistics & & \multicolumn{3}{|c|}{$P=0.030$} & \multicolumn{3}{|c|}{$P=0.008$} & NS & \multicolumn{2}{|c|}{$P<0.001$} \\
\hline
\end{tabular}

mRNA TP expression (a.u.)

\begin{tabular}{|l|c|c|c|c|c|c|}
\hline Median & 3.75 & & & & \\
Mean & 5.45 & & & & \\
Extremes & $0.07-43.40$ & & & & \\
$\mathrm{~N}$ & 238 & & & & \\
\hline Statistics & & NS & NS & & \\
\hline
\end{tabular}

mRNA DPD expression (a.u.)

\begin{tabular}{|c|c|c|c|c|c|c|c|c|c|c|c|c|}
\hline Median & 9 & 5.1 & 9.9 & 9.5 & 13.8 & 6.7 & 8.7 & 8 & 9.1 & 17.7 & 11.4 & 7.3 \\
\hline Mean & 14.6 & 10.3 & 15.2 & 15.2 & 18.9 & 11.8 & 12.9 & 12.7 & 15.3 & 27.8 & 16.6 & 10.2 \\
\hline Extremes & ND to 103.5 & & & & & & & & & & & \\
\hline $\mathrm{N}$ & 238 & 29 & 113 & 96 & 89 & 117 & 31 & 138 & 85 & 15 & 83 & 132 \\
\hline Statistics & & \multicolumn{3}{|c|}{$P=0.032$} & \multicolumn{3}{|c|}{$P<0.001$} & \multicolumn{3}{|c|}{$P=0.005$} & \multicolumn{2}{|c|}{$P=0.002$} \\
\hline
\end{tabular}

TP expression/DPD expression ${ }^{b}$

\begin{tabular}{|l|c|c|c|c|c|}
\hline Median & 0.42 & & & \\
Eean & 1.32 & & & \\
$\mathrm{~N}$ & $0.01-118$ & & & \\
\hline Statistics & 238 & & NS & NS & NS \\
\hline
\end{tabular}

Abbreviations: $a . u$. = arbitrary unit; $\mathrm{DPD}=$ dihydropyrimidine dehydrogenase; $\mathrm{EGFR}=$ epidermal growth factor receptor; $\mathrm{LC}=$ left $\mathrm{colon} ; \mathrm{ND}=\mathrm{not}$ detectable; $\mathrm{NS}=$ nonsignificant; $\mathrm{RC}=$ right colon; RSJ = recto-sigmoid junction; $\mathrm{TC}=$ transverse colon; $\mathrm{TP}=$ thymidine phosphorylase; $\mathrm{TS}=$ thymidylate synthase; $\mathrm{VEGF}=$ vascular endothelial growth factor.

${ }^{a}$ Comparisons of distribution of quantitative tumoral expressions (taken as continuous variables) as a function of categorical tumour characteristics were tested with the non-parametric KruskallWallis test (for three-group comparison) or Mann-Whitney test (for two-group comparison). P-values are given.

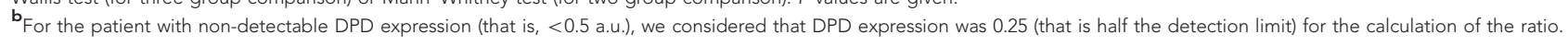

setting (5FU-treated patients), including ours (Etienne et al, 2002), have reported that elevated TS expression was associated with shorter OS (combined HR 1.74), whereas - in the adjuvant setting - restricting the meta-analysis to patients treated with surgery plus 5FU-based adjuvant treatment did not show influence of TS expression on OS or PFS (pool HR 0.93 and 1, 
Table 3. Significant relationships between quantitative tumour expression and tumour DNA features ${ }^{\mathrm{a}}$

Allelic loss

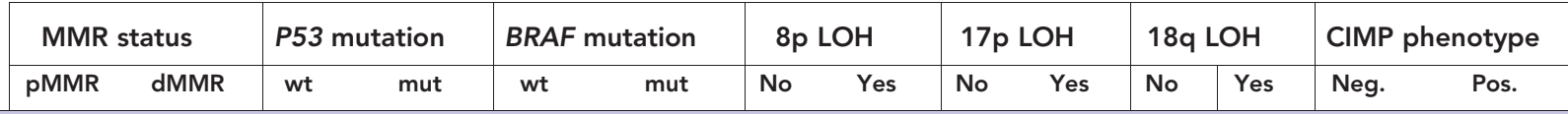

Membranous EGFR ( $\mathrm{fmol} \mathrm{mg}^{-1}$ protein)

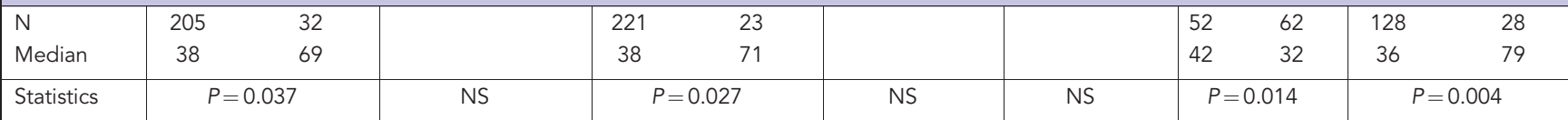

\section{Cytosolic VEGF (pg mg ${ }^{-1}$ protein)}

\begin{tabular}{|c|c|c|c|c|c|c|c|c|c|c|c|c|c|c|}
\hline $\begin{array}{l}\mathrm{N} \\
\text { Median }\end{array}$ & & & $\begin{array}{l}125 \\
258\end{array}$ & $\begin{array}{l}119 \\
360\end{array}$ & & & & & $\begin{array}{c}44 \\
251\end{array}$ & $\begin{array}{c}75 \\
433\end{array}$ & $\begin{array}{c}53 \\
280\end{array}$ & & & \\
\hline Statistics & & & & & & & & VS & & & & & & \\
\hline \multicolumn{15}{|c|}{ Cytosolic TS activity ( $\mathrm{fmol} \mathrm{min}^{-1}$ per $\mathrm{mg}$ protein) } \\
\hline $\begin{array}{l}\mathrm{N} \\
\text { Median }\end{array}$ & $\begin{array}{c}209 \\
1040\end{array}$ & $\begin{array}{c}34 \\
2630\end{array}$ & & & $\begin{array}{c}226 \\
1045\end{array}$ & $\begin{array}{c}24 \\
3014\end{array}$ & $\begin{array}{c}69 \\
803\end{array}$ & $\begin{array}{c}46 \\
1460\end{array}$ & & & & & $\begin{array}{c}130 \\
1074\end{array}$ & $\begin{array}{c}28 \\
2624\end{array}$ \\
\hline Statistics & \multicolumn{2}{|c|}{$P=0.004$} & \multicolumn{2}{|c|}{ NS } & \multicolumn{2}{|c|}{$P=0.032$} & \multicolumn{2}{|c|}{$P=0.011$} & \multicolumn{2}{|c|}{ NS } & \multicolumn{2}{|c|}{ NS } & \multicolumn{2}{|c|}{$P=0.001$} \\
\hline
\end{tabular}

mRNA TS expression (a.u.)

\begin{tabular}{|c|c|c|c|c|c|c|c|c|c|c|c|c|}
\hline $\begin{array}{l}\mathrm{N} \\
\text { Median }\end{array}$ & $\begin{array}{l}200 \\
1.39\end{array}$ & $\begin{array}{c}31 \\
3.07\end{array}$ & $\begin{array}{l}118 \\
1.98\end{array}$ & $\begin{array}{l}115 \\
1.23\end{array}$ & $\begin{array}{l}214 \\
1.43\end{array}$ & $\begin{array}{c}23 \\
2.63\end{array}$ & & & \begin{tabular}{|c|}
52 \\
1.74
\end{tabular} & $\begin{array}{c}62 \\
1.13\end{array}$ & $\begin{array}{l}129 \\
1.41\end{array}$ & $\begin{array}{c}28 \\
2.13\end{array}$ \\
\hline Statistics & \multicolumn{2}{|c|}{$P<0.001$} & \multicolumn{2}{|c|}{$P<0.001$} & \multicolumn{2}{|c|}{$P=0.005$} & NS & NS & \multicolumn{2}{|c|}{$P=0.011$} & \multicolumn{2}{|c|}{$P=0.029$} \\
\hline
\end{tabular}

mRNA TP expression (a.u.)

\begin{tabular}{|c|c|c|c|c|c|c|c|c|c|c|}
\hline $\begin{array}{l}\mathrm{N} \\
\text { Median }\end{array}$ & $\begin{array}{l}200 \\
3.48\end{array}$ & $\begin{array}{c}31 \\
5.77\end{array}$ & $\begin{array}{l}118 \\
4.17\end{array}$ & $\begin{array}{l}115 \\
3.35\end{array}$ & $\begin{array}{l}214 \\
3.59\end{array}$ & $\begin{array}{c}23 \\
4.80\end{array}$ & & & & \\
\hline Statistics & & & & & & & NS & NS & NS & NS \\
\hline
\end{tabular}

mRNA DPD expression (a.u.)

\begin{tabular}{|c|c|c|c|c|c|c|c|c|c|c|c|c|c|}
\hline $\begin{array}{l}\mathrm{N} \\
\text { Median }\end{array}$ & $\begin{array}{l}200 \\
7.9\end{array}$ & $\begin{array}{c}31 \\
14.9\end{array}$ & $\begin{array}{c}118 \\
12.7\end{array}$ & $\begin{array}{l}115 \\
7.1\end{array}$ & & $\begin{array}{c}67 \\
11.9\end{array}$ & $\begin{array}{l}45 \\
6.1\end{array}$ & $\begin{array}{c}42 \\
14.2\end{array}$ & $\begin{array}{l}72 \\
6.7\end{array}$ & \begin{tabular}{|c|}
52 \\
12.9
\end{tabular} & $\begin{array}{l}62 \\
6.4\end{array}$ & $\begin{array}{l}129 \\
7.6\end{array}$ & $\begin{array}{c}28 \\
15.6\end{array}$ \\
\hline Statistics & & & & & NS & & 03 & & 01 & & 02 & & \\
\hline
\end{tabular}

TP expression/DPD expression ${ }^{b}$

\begin{tabular}{|l|c|c|c|c|c|c|c|}
\hline N & 200 & 31 & & & 42 & 72 & \\
Median & 0.41 & 0.55 & & & 0.34 & 0.47 & \\
\hline Statistics & $P=0.029$ & NS & NS & NS & $P=0.035$ \\
\hline
\end{tabular}

Abbreviations: $\mathrm{CIMP}=\mathrm{CpG}$ island methylation phenotype; $\mathrm{dMMR}=$ deficient mismatch repair; $\mathrm{DPD}=$ dihydropyrimidine dehydrogenase; $\mathrm{LOH}=$ loss of heterozygosity; $\mathrm{MMR}=$ mismatch repair; $\mathrm{ND}=$ not detectable; $\mathrm{NS}=$ nonsignificant; $\mathrm{pMMR}=$ proficient mismatch repair; $\mathrm{TP}=$ thymidine phosphorylase; $\mathrm{TS}=$ thymidylate synthase

${ }^{a}$ Comparisons of distribution of quantitative tumoral expressions as a function of tumour DNA features were tested with the non-parametric Kruskall-Wallis test.

${ }^{b_{F}}$ or the patient with non-detectable DPD expression (that is, < 0.5 a.u.), we considered that DPD expression was 0.25 (that is, half the detection limit) for the calculation of the ratio.

respectively). In contrast, the meta-analysis restricted to patients receiving surgery only showed a significant $\mathrm{HR}$ at 1.92 and 1.90 for OS and PFS, respectively, in patients with elevated TS expression relative to others (Popat et al, 2004). Thus, elevated tumour TS expression appears to be associated with poor prognosis in CRC.

The originality and strength of this study stem from the richness of the relationships between these protein markers and conventional tumour markers (Tables 2 and 3). None of the above-cited tumour proteins were significantly related to tumour staging. However, distribution of EGFR, TS and DPD expression differed according to tumour localisation (Table 2). These biological differences support recent data showing that left- and right-sided CRC are characterised by distinct clinicopathological and molecular features (Missiaglia et al, 2013; Popovici et al, 2013; Sinicrope et al, 2013). Of note, a recent study conducted on 2580 stage III colon cancer patients receiving FOLFOX-based treatment reported that the favourable prognostic value of dMMR status was restricted to the right colon tumours (Sinicrope et al, 2013).

Importantly, dMMR tumours tend to express a higher EGFR content relative to pMMR (median 69 vs 38 units, $P=0.037$ ). Even though tumour EGFR expression measured by IHC has never been shown to be predictive of anti-EGFR monoclonal antibody $(\mathrm{mAb})$ efficacy, the fact that dMMR tumours tend to express elevated EGFR levels measured by a specific binding assay, and are prone to be KRAS wt, suggests that the impact of MMR status on the efficacy of anti-EGFR mAb should be explored more thoroughly. 


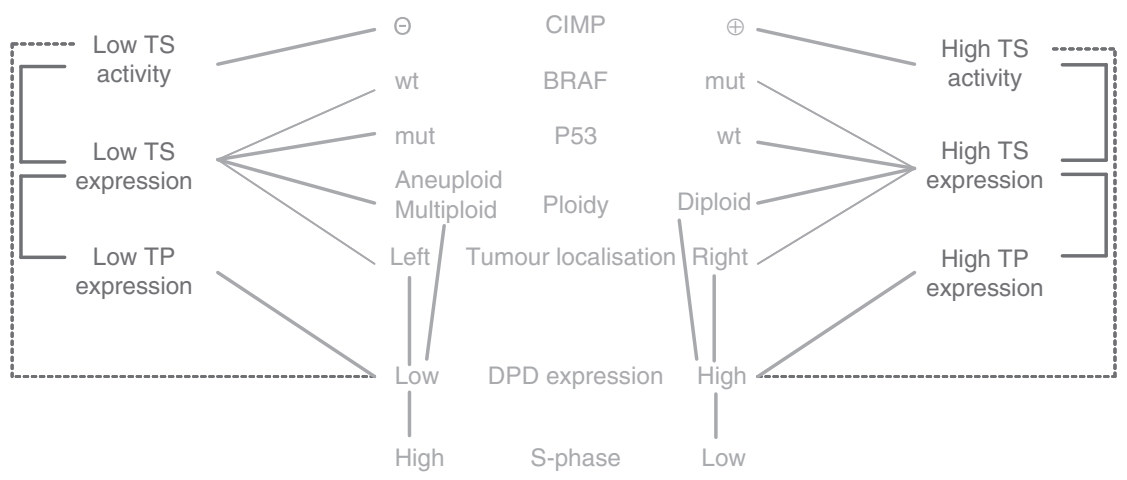

Figure 3. Exhaustive summary of tumoral protein expression (in blue) related to MMR status in the present study (TS and TP expressions, $P<0.001$; TS activity, $P=0.004$ ), and their associations with additional tumour characteristics (in orange). Connecting lines in blue indicate associations between protein expression, and connecting lines in orange indicate associations between protein expression and additional tumour characteristics. All relationships with $P \leqslant 0.01$ are reported. The thickness of the lines indicates the significance of the relationship (thick lines for $P \leqslant 0.001$; thin lines for $0.01 \leqslant P<0.001$ ). Full lines indicate significant positive relationships. The dotted line indicates a negative correlation (inverse relationship between TS activity and DPD expressions, $r=-0.23, P<0.001$ ). The full colour version of this figure is available at British Journal of Cancer online.

Given the intrinsic key role of MMR status in CRC aetiology and prognosis (Popat et al, 2005), we attempted to summarise tumour expression features that were related to MMR status in Figure 3. To our knowledge, present data reveal for the first time that dMMR tumours significantly exhibit elevated protein expression for TS and TP, whereas pMMR tumours express low levels of these protein markers. Of note, CIMP + tumours, such as BRAF mut, p53 wt, diploid and right colon tumours, were prone to express high TS activity and/or expression. These observations are highly consistent with each other, considering that dMMR tumours are associated with CIMP +, BRAF mut, p53 wt, diploidy and right-side localisation. Despite a weak negative correlation between TS activity and DPD expression, dMMR tumours tend to express a two-fold higher DPD expression as compared with pMMR $(P=0.027$, Table 3$)$. Despite a relative low statistical power, based on a limited population of 32 dMMR tumours and 205 pMMR tumours, the present study provides original and relevant preliminary new knowledge associated with MMR status. These data would merit further confirmation on a larger set of patients.

Resistance to 5FU has been linked to TS overexpression, as reported by previous investigators (Longley et al, 2003) and us (Etienne et al, 2002). In addition, elevated intratumoural DPD expression results in an increased fluoropyrimidine catabolism at the expense of anabolism, and may cause fluoropyrimidine resistance, as recently shown by others (Gustavsson et al, 2009) and us at the preclinical (Beck et al, 1994) and clinical levels (Etienne et al, 1999). Two randomized trials of 5FU-based adjuvant therapy $v s$ no treatment have reported that stage II-III patients bearing dMMR tumours do not benefit from 5FU-based therapy (Ribic et al, 2003; Sargent et al, 2010). In addition, a meta-analysis by Popat et al (2005) confirmed a significant survival advantage for 5FU-based adjuvant therapy in stage II-III pMMR patients (combined $\mathrm{HR}=0.72, P=0.007$ ), whereas dMMR patients drew no benefit from 5FU-based treatment (combined $\mathrm{HR}=1.24$, NS). Moreover, a recent pooled retrospective study conducted on 2141 stage II-III colon cancer patients from several adjuvant trials (5FU-based treatment $v s$ surgery alone) demonstrated that the subgroup of dMMR (suspected to be sporadic tumours) did not draw benefit from 5FU-based therapy (Sinicrope et al, 2011).
The present original data suggesting that both TS and DPD are overexpressed in dMMR tumours as compared with pMMR tumours provide a strong rationale that may explain the resistance of dMMR tumours to fluoropyrimidines, which still remain the reference therapeutic class in the chemotherapy of CRC. In conclusion, this study provides preliminary new molecular knowledge on dMMR colorectal tumours, specifically at the level of pivotal enzymes involved in 5FU pharmacodynamics. We hope the present results will be confirmed in further studies. Such confirmation may be of practical value for future optimal therapeutic management of CCR patients, as expected in the current era of personalised medicine.

\section{ACKNOWLEDGEMENTS}

We would like to thank the Ligue Nationale Contre le Cancer (CIT program) for PIK3CA, APC and CIMP analyses and the GERCOR group for logistic and data management. This study was supported by the French Research Ministry (Programme Hospitalier de Recherche Clinique).

\section{CONFLICT OF INTEREST}

The authors declare no conflict of interest.

\section{REFERENCES}

Andreyev HJ, Norman AR, Cunningham D, Oates JR, Clarke PA (1998) Kirsten ras mutations in patients with colorectal cancer: the multicenter "RASCAL" study. J Natl Cancer Inst 90: 675-684.

Andreyev HJ, Norman AR, Cunningham D, Oates J, Dix BR, Iacopetta BJ, Young J, Walsh T, Ward R, Hawkins N, Beranek M, Jandik P, Benamouzig R, Jullian E, Laurent-Puig P, Olschwang S, Muller O, Hoffmann I, Rabes HM, Zietz C, Troungos C, Valavanis C, Yuen ST, Ho JW, Croke CT,

O'Donoghue DP, Giaretti W, Rapallo A, Russo A, Bazan V, Tanaka M, Omura K, Azuma T, Ohkusa T, Fujimori T, Ono Y, Pauly M, Faber C, Glaesener R, de Goeij AF, Arends JW, Andersen SN, Lövig T, Breivik J, Gaudernack G, Clausen OP, De Angelis PD, Meling GI, Rognum TO, Smith R, Goh HS, Font A, Rosell R, Sun XF, Zhang H, Benhattar J, Losi L, 
Lee JQ, Wang ST, Clarke PA, Bell S, Quirke P, Bubb VJ, Piris J, Cruickshank NR, Morton D, Fox JC, Al-Mulla F, Lees N, Hall CN, Snary D, Wilkinson K, Dillon D, Costa J, Pricolo VE, Finkelstein SD, Thebo JS, Senagore AJ, Halter SA, Wadler S, Malik S, Krtolica K, Urosevic N (2001) Kirsten ras mutations in patients with colorectal cancer: the 'RASCAL II' study. Br J Cancer 85: 692-696.

Beck A, Etienne MC, Chéradame S, Fischel JL, Formento P, Renée N, Milano G (1994) A role for dihydropyrimidine dehydrogenase and thymidylate synthase in tumour sensitivity to fluorouracil. Eur J Cancer 30A: 1517-1522.

Bertagnolli MM, Redston M, Compton CC, Niedzwiecki D, Mayer RJ, Goldberg RM, Colacchio TA, Saltz LB, Warren RS (2011) Microsatellite instability and loss of heterozygosity at chromosomal location 18q: prospective evaluation of biomarkers for stages II and III colon cancer-a study of CALGB 9581 and 89803. J Clin Oncol 29: 3153-3162.

Burrell RA, McClelland SE, Endesfelder D, Groth P, Weller MC, Shaikh N, Domingo E, Kanu N, Dewhurst SM, Gronroos E, Chew SK, Rowan AJ, Schenk A, Sheffer M, Howell M, Kschischo M, Behrens A, Helleday T, Bartek J, Tomlinson IP, Swanton C (2013) Replication stress links structural and numerical cancer chromosomal instability. Nature 494: 492-496.

Cancer Genome Atlas Network (2012) Comprehensive molecular characterization of human colon and rectal cancer. Nature 487: 330-337.

Eklöf V, Wikberg ML, Edin S, Dahlin AM, Jonsson BA, Öberg A, Rutegård J, Palmqvist R (2013) The prognostic role of KRAS, BRAF, PIK3CA and PTEN in colorectal cancer. Br J Cancer 108: 2153-2163.

Etienne MC, Pivot X, Formento JL, Bensadoun RJ, Formento P, Dassonville O, Francoual M, Poissonnet G, Fontana X, Schneider M, Demard F, Milano G (1999) A multifactorial approach including tumoural epidermal growth factor receptor, p53, thymidylate synthase and dihydropyrimidine dehydrogenase to predict treatment outcome in head and neck cancer patients receiving 5-fluorouracil. Br J Cancer 79: 1864-1869.

Etienne MC, Chazal M, Laurent-Puig P, Magné N, Rosty C, Formento JL, Francoual M, Formento P, Renée N, Chamorey E, Bourgeon A, Seitz JF, Delpero JR, Letoublon C, Pezet D, Milano G (2002) Prognostic value of tumoral thymidylate synthase and p53 in metastatic colorectal cancer patients receiving fluorouracil-based chemotherapy: phenotypic and genotypic analyses. J Clin Oncol 20: 2832-2843.

Etienne-Grimaldi MC, Cayre A, Penault-Llorca F, Francoual M, Formento JL, Benchimol D, Bourgeon A, Milano G (2006) EGFR expression in colon cancer: a break in the clouds. Ann Oncol 17(12): 1850-1851.

Gavin PG, Colangelo LH, Fumagalli D, Tanaka N, Remillard MY, Yothers G, Kim C, Taniyama Y, Kim SI, Choi HJ, Blackmon NL, Lipchik C, Petrelli NJ, O'Connell MJ, Wolmark N, Paik S, Pogue-Geile KL (2012) Mutation profiling and microsatellite instability in stage II and III colon cancer: an assessment of their prognostic and oxaliplatin predictive value. Clin Cancer Res 18: 6531-6541.

Grady WM, Carethers JM (2008) Genomic and epigenetic instability in colorectal cancer pathogenesis. Gastroenterology 135: 1079-1099.

Gustavsson B, Kaiser C, Carlsson G, Wettergren Y, Odin E, Lindskog EB, Niyikiza C, Ma D (2009) Molecular determinants of efficacy for 5-FU-based treatments in advanced colorectal cancer: mRNA expression for 18 chemotherapy-related genes. Int J Cancer 124: 1220-1226.

Hutchins G, Southward K, Handley K, Magill L, Beaumont C, Stahlschmidt J, Richman S, Chambers P, Seymour M, Kerr D, Gray R, Quirke P (2011) Value of mismatch repair, KRAS, and BRAF mutations in predicting recurrence and benefits from chemotherapy in colorectal cancer. J Clin Oncol 29: 1261-1270.

Liao X, Morikawa T, Lochhead P, Imamura Y, Kuchiba A, Yamauchi M, Nosho K, Qian ZR, Nishihara R, Meyerhardt JA, Fuchs CS, Ogino S (2012) Prognostic role of PIK3CA mutation in colorectal cancer: cohort study and literature review. Clin Cancer Res 18: 2257-2268.

Lochhead P, Kuchiba A, Imamura Y, Liao X, Yamauchi M, Nishihara R, Qian ZR, Morikawa T, Shen J, Meyerhardt JA, Fuchs CS, Ogino S (2013) Microsatellite instability and BRAF mutation testing in colorectal cancer prognostication. J Natl Cancer Inst 105: 1151-1156.

Longley DB, Harkin DP, Johnston PG (2003) 5-fluorouracil: mechanisms of action and clinical strategies. Nat Rev Cancer 3: 330-338.

Magné N, Fischel JL, Dubreuil A, Formento P, Poupon MF, Laurent-Puig P, Milano G (2002) Influence of epidermal growth factor receptor (EGFR), p53 and intrinsic MAP kinase pathway status of tumour cells on the antiproliferative effect of ZD1839 ("Iressa"). Br J Cancer 86(9): $1518-1523$.
Merok MA, Ahlquist T, Røyrvik EC, Tufteland KF, Hektoen M, Sjo OH, Mala T, Svindland A, Lothe RA, Nesbakken A (2013) Microsatellite instability has a positive prognostic impact on stage II colorectal cancer after complete resection: results from a large, consecutive Norwegian series. Ann Oncol 24: 1274-1282.

Missiaglia E, Jacobs B, Di Narzo FA, Soneson C, Roth A, Bosman F, D’Ario G, Klingbiel D, Yan P, Delorenzi M, Tejpar S (2013) Proximal and distal colon tumours as distinct biologic entities with different prognoses. J Clin Oncol 31(suppl): abstr 3526.

Ogino S, Meyerhardt JA, Irahara N, Niedzwiecki D, Hollis D, Saltz LB, Mayer RJ, Schaefer P, Whittom R, Hantel A, Benson 3rd AB, Goldberg RM, Bertagnolli MM, Fuchs CS. Cancer and Leukemia Group B; North Central Cancer Treatment Group; Canadian Cancer Society Research Institute; Southwest Oncology Group (2009a) KRAS mutation in stage III colon cancer and clinical outcome following intergroup trial CALGB 89803. Clin Cancer Res 15: 7322-7329.

Ogino S, Nosho K, Kirkner GJ, Kawasaki T, Meyerhardt JA, Loda M, Giovannucci EL, Fuchs CS (2009b) CpG island methylator phenotype, microsatellite instability, BRAF mutation and clinical outcome in colon cancer. Gut 58: 90-96.

Onesto C, Hannoun-Lévi JM, Chamorey E, Formento JL, Ramaioli A, Pagès G (2006) Vascular endothelial growth factor-A and Poly(A) binding protein-interacting protein 2 expression in human head and neck carcinomas: correlation and prognostic significance. Br J Cancer 94: 1516-1523.

Popat S, Matakidou A, Houlston RS (2004) Thymidylate synthase expression and prognosis in colorectal cancer: a systematic review and meta-analysis. $J$ Clin Oncol 22: 529-536.

Popat S, Hubner R, Houlston RS (2005) Systematic review of microsatellite instability and colorectal cancer prognosis. J Clin Oncol. 23: 609-618.

Popovici VC, Budinska E, Roth A, Bosman F, Tejpar S, Delorenzi M (2013) BRAF and KRAS mutations as additional risk factors in the context of clinical parameters of patients with colorectal cancer. J Clin Oncol 31(suppl): abstr 3522.

Quasar Collaborative GroupGray R, Barnwell J, McConkey C, Hills RK, Williams NS, Kerr DJ (2007) Adjuvant chemotherapy versus observation in patients with colorectal cancer: a randomised study. Lancet 370: 2020-2029.

Ribic CM, Sargent DJ, Moore MJ, Thibodeau SN, French AJ, Goldberg RM, Hamilton SR, Laurent-Puig P, Gryfe R, Shepherd LE, Tu D, Redston M, Gallinger S (2003) Tumor microsatellite-instability status as a predictor of benefit from fluorouracil-based adjuvant chemotherapy for colon cancer. N Engl J Med 349: 247-257.

Richman SD, Seymour MT, Chambers P, Elliott F, Daly CL, Meade AM, Taylor G, Barrett JH, Quirke P (2009) KRAS and BRAF mutations in advanced colorectal cancer are associated with poor prognosis but do not preclude benefit from oxaliplatin or irinotecan: results from the MRC FOCUS trial. J Clin Oncol 27: 5931-5937.

Roth AD, Tejpar S, Delorenzi M, Yan P, Fiocca R, Klingbiel D, Dietrich D, Biesmans B, Bodoky G, Barone C, Aranda E, Nordlinger B, Cisar L, Labianca R, Cunningham D, Van Cutsem E, Bosman F (2010) Prognostic role of KRAS and BRAF in stage II and III resected colon cancer: results of the translational study on the PETACC-3, EORTC 40993, SAKK 60-00 trial. J Clin Oncol 28: 466-474.

Roth AD, Delorenzi M, Tejpar S, Yan P, Klingbiel D, Fiocca R, d'Ario G, Cisar L, Labianca R, Cunningham D, Nordlinger B, Bosman F, Van Cutsem E (2012) Integrated analysis of molecular and clinical prognostic factors in stage II/III colon cancer. J Natl Cancer Inst 104: $1635-1646$.

Santini J, Formento JL, Francoual M, Milano G, Schneider M, Dassonville O, Demard F (1991) Characterization, quantification, and potential clinical value of the epidermal growth factor receptor in head and neck squamous cell carcinomas. Head Neck 13: 132-139.

Sargent DJ, Marsoni S, Monges G, Thibodeau SN, Labianca R, Hamilton SR, French AJ, Kabat B, Foster NR, Torri V, Ribic C, Grothey A, Moore M, Zaniboni A, Seitz JF, Sinicrope F, Gallinger S (2010) Defective mismatch repair as a predictive marker for lack of efficacy of fluorouracil-based adjuvant therapy in colon cancer. J Clin Oncol 28: 3219-3226.

Sinicrope FA, Foster NR, Thibodeau SN, Marsoni S, Monges G, Labianca R, Kim GP, Yothers G, Allegra C, Moore MJ, Gallinger S, Sargent DJ (2011) DNA mismatch repair status and colon cancer recurrence and survival in clinical trials of 5-fluorouracil-based adjuvant therapy. J Natl Cancer Inst 103: $863-875$. 
Sinicrope FA, Sargent DJ (2012) Molecular pathways: microsatellite instability in colorectal cancer: prognostic, predictive, and therapeutic implications. Clin Cancer Res 18: 1506-1512.

Sinicrope FA, Mahoney MR, Smyrk TC, Thibodeau SN, Warren RS, Bertagnolli MM, Nelson GD, Goldberg RM, Sargent DJ, Alberts SR (2013) Prognostic impact of deficient DNA mismatch repair in patients with stage III colon cancer from a randomized trial of FOLFOX-based adjuvant chemotherapy. J Clin Oncol 31: 3664-3672.

Souglakos J, Philips J, Wang R, Marwah S, Silver M, Tzardi M, Silver J, Ogino S, Hooshmand S, Kwak E, Freed E, Meyerhardt JA, Saridaki Z, Georgoulias V, Finkelstein D, Fuchs CS, Kulke MH, Shivdasani RA (2009) Prognostic and predictive value of common mutations for treatment response and survival in patients with metastatic colorectal cancer. Br J Cancer 101: 465-472.
Ueno H, Mochizuki H, Akagi Y, Kusumi T, Yamada K, Ikegami M, Kawachi H, Kameoka S, Ohkura Y, Masaki T, Kushima R, Takahashi K, Ajioka Y, Hase K, Ochiai A, Wada R, Iwaya K, Shimazaki H, Nakamura T, Sugihara K (2012) Optimal colorectal cancer staging criteria in TNM classification. J Clin Oncol 30: 1519-1526.

Van Schaeybroeck S, Allen WL, Turkington RC, Johnston PG (2011) Implementing prognostic and predictive biomarkers in CRC clinical trials. Nat Rev Clin Oncol 8: 222-232.

This work is published under the standard license to publish agreement. After 12 months the work will become freely available and the license terms will switch to a Creative Commons AttributionNonCommercial-Share Alike 3.0 Unported License.

Supplementary Information accompanies this paper on British Journal of Cancer website (http://www.nature.com/bjc) 